\title{
Value of Pharmacologic Stress Myocardial Perfusion Imaging for Preoperative Risk Stratification for Aortic Surgery
}

\author{
Katsufumi Harafuji, MD; Taishiro Chikamori, MD; Satoshi Kawaguchi, MD*; Yukio Obitsu, MD*; \\ Shigeki Ito, MD*; Yuko Igarashi, MD; Hirokazu Tanaka, MD; Yasuhiro Usui, MD; \\ Satoshi Hida, MD; Shin Ishimaru, MD*; Akira Yamashina, MD
}

\begin{abstract}
Background Aortic surgery is an invasive, high-risk noncardiac procedure and the patients who require it have a high prevalence of coronary artery disease. Therefore, preoperative risk stratification for this subset is essential. Methods and Results To assess the perioperative risk for aortic surgery, pharmacologic stress single-photon emission computed tomography (SPECT) was performed in 302 patients: aortic dissection in 56, thoracic aortic aneurysm in 124, and abdominal aortic aneurysm in 122. Not only was the presence or absence of perfusion defects analyzed, but also the 20-segment model. Pharmacologic thallium SPECT revealed negative findings in 210 patients and positives in 92 . Perioperative cardiac events occurred in 9 patients: 7 occurred in patients with positive SPECT, and in only 2 of those with negative SPECT ( $2 / 210$ vs $7 / 92 ; p<0.05)$. Multivariate analysis using logistic regression model revealed that a summed stress score $\geq 14$ was the most important factor to identify patients who subsequently had perioperative cardiac events.

Conclusions Pharmacologic stress SPECT has significant value in the risk stratification of patients before aortic surgery. In patients with positive SPECT, an aggressive approach to reduce the preoperative risk is necessary, whereas aortic surgery can be performed safely in patients with negative SPECT. (Circ J 2005; 69: 558-563)
\end{abstract}

Key Words: Aortic surgery; Myocardial perfusion imaging; Perioperative cardiac event; Preoperative risk stratification

$\mathbf{E}$ valuating the risk of perioperative cardiac events related to noncardiac surgery is important ${ }^{1-9}$ Preoperative myocardial perfusion imaging is useful for further stratification of the risk in moderate- and highrisk patients ${ }^{3,4}$ because the redistribution findings can be used as predictive factors for cardiac events, and the technique has a high negative predictive value ${ }^{5-8}$ Moreover, recent studies suggest that the likelihood of cardiac events increases with the severity of the defect score on images evaluated semi-quantitatively $y^{4,6-9}$ and guidelines for the perioperative cardiovascular evaluation of noncardiac surgery patients were recently published by the ACC/AHA, providing a framework for weighting the cardiac risk of noncardiac surgery based on patients' risk profiles and the type of operation ${ }^{10}$ Of the procedures, aortic surgery is claimed to be high-risk (the reported cardiac risk is often $\geq 5 \%$ ), not only because it is highly invasiveness surgery but also because of the high prevalence of coronary artery disease in patients with aortic diseases $!^{10-12}$ However, there are few studies regarding preoperative risk stratification in Japanese patients who undergo aortic surgery!3,14 Thus, the present study evaluated whether perioperative cardiac events related to aortic surgery can be predicted by preoperative pharmacologic stress myocardial perfusion imaging.

(Received November 25, 2004; revised manuscript received January 31, 2005; accepted February 9, 2005)

Departments of Internal Medicine II, *Surgery II, Tokyo Medical University, Tokyo, Japan

Mailing address: Katsufumi Harafuji, MD, Department of Internal Medicine II, Tokyo Medical University, 6-7-1 Nishi-Shinjuku, Shinjuku-ku, Tokyo 160-0023, Japan. E-mail: fwnf8022@mb. infoweb.ne.jp

\section{Methods}

Subjects

The subjects of this study were 302 consecutive patients who underwent elective aortic surgery after pharmacologic stress single-photon emission computed tomography (SPECT) between January 1998 and August 2003. SPECT study was performed in all patients unless contraindications such as bronchial asthma and advanced heart block were present. There were 261 men and 41 women, aged $71 \pm 10$ years (35-86 years); 128 of them $(42 \%)$ were aged 75 years or older. Medical history of angina pectoris was noted in 19 patients, myocardial infarction (MI) in 26, and heart failure in $5 ; 19$ of them had undergone coronary revascularization. Hypertension was found in 217 patients, hypercholesterolemia in 73, diabetes mellitus (DM) in 55, and renal insufficiency defined as serum creatinine level $\geq 2.0 \mathrm{mg} / \mathrm{dl}$ in 20 .

The etiologies of the aortic diseases were type B aortic dissection in 56 patients, thoracic aortic aneurysm in 124, and abdominal aortic aneurysm in 122. The indication for aortic surgery was decided by cardiovascular surgeons based on the anatomical and pathological indications $!^{15-18}$ The type of surgery was conventional open surgery in 75 patients and endovascular surgery with stent-graft placement in 227. Aortic surgery including stent-graft placement was performed under general anesthesia. Approval to perform the endovascular surgery was obtained from the Ethical Committee of Tokyo Medical University. Written informed consent was obtained from all of the patients.

Stress Myocardial Scintigraphy

Pharmacologic stress SPECT was performed $\geq 15 \mathrm{~h}$ after 


\section{SHORT AXIS}

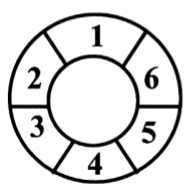

Apical

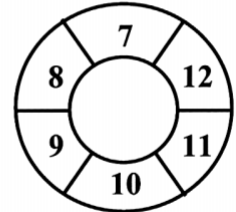

Mid

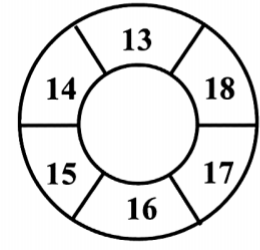

Basal

\section{VERTCAL LONG AXIS}

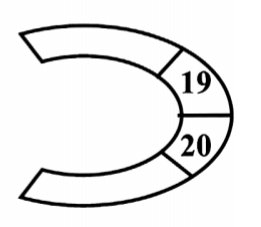

Fig 1. Assignment of the myocardial regions for scoring of SPECT images. the cessation of cardioactive medications. For the stress, adenosine triphosphate disodium (ATP) was used in 239 patients and dipyridamole in 63. ATP was infused at $0.16 \mathrm{mg} / \mathrm{kg}$ over $5 \mathrm{~min}$, and $2 \mathrm{~min}$ before the end of infusion, $111 \mathrm{MBq}$ of thallium-201 $\left({ }^{201} \mathrm{Tl}\right)$ was injected intravenously. Dipyridamole was infused at $0.142 \mathrm{mg} / \mathrm{kg}$ over $4 \mathrm{~min}$, and $3 \mathrm{~min}$ after the end of infusion, $111 \mathrm{MBq}$ of ${ }^{201} \mathrm{Tl}$ was injected intravenously. Ten minutes after pharmacologic stress, image acquisition was started. Delayed images were obtained $4 \mathrm{~h}$ later. Data was acquired with a 2- or 3detector gamma camera (Prism 2000XP or Prism 3000XP, Picker, Cleveland, OH, USA) using a low-energy, highresolution parallel multi-hole collimator. Image reconstruction was conducted on an image data processor (Odyssey VP, Picker) using a Butterworth filter (with a cutoff value of 0.25 and an order of 8 ) and a ramp filter 19

The SPECT image was considered positive if either reversible or fixed defects were present. According to a method reported elsewhere ${ }^{20}$ each SPECT image was divided into 20 segments, with segments 1-3, 7-9, 13-14 and 19-20 corresponding to the areas perfused by the left anterior descending coronary artery, segments 4, 10 and 15-16 corresponding to the areas perfused by the right coronary artery, and segments 5-6, 11-12 and 17-18 corresponding to the areas perfused by the left circumflex coronary artery (Fig 1). The accumulation of radioisotope in the myocardium was visually evaluated by 2 cardiologists using a 5-grade scale: 0 (normal), 1 (slight reduction of uptake), 2 (moderate reduction of uptake), 3 (severe reduction of uptake) or 4 (absent of radioactive uptake). Disagreements in image interpretation were resolved by consensus. The total of the scores for all the segments during stress and at rest was designated as the summed stress score (SSS) and the summed rest score, respectively. A SSS of $\geq 14$ was considered to indicate severe coronary artery disease, because this cutoff value has been previously reported as identifying a high-risk group for future cardiac events. $21-23$

\section{Cardiac Catheterization}

The indication for coronary angiography before aortic surgery was decided by the attending physicians based on the clinical risk profiles of patients, results of noninvasive tests, and patients' preference. Multi-direction coronary angiography was performed according to the Judkins' method. The degree of coronary artery stenosis was visually rated using a caliper, according to the American Heart Association.24 A significant stenosis was deemed as present if $\geq 75 \%$ narrowing of the diameter was noted. For all patients who underwent cardiac catheterization, the treatment strategy was discussed in a clinical conference of the primary physicians, nuclear cardiologists, interventional cardiologists and cardiovascular surgeons.

\section{Perioperative and Postoperative Care}

Patient management was entirely dictated by the treating physicians, who were aware of the results of the preoperative pharmacologic stress SPECT. In general, patients with evidence of ischemia on stress SPECT received antianginal medications during and after operation and had intraoperative hemodynamic monitoring with a pulmonary artery catheter. Standard electrocardiographic monitoring was used for the remaining patients. However, no attempt was made to standardize care.

\section{Perioperative Cardiac Events}

Perioperative cardiac events were defined if the following events occurred within 30 days postoperatively. Cardiac death was defined as death caused by acute MI, fatal cardiac arrhythmias, or refractory congestive heart failure (CHF). The diagnosis of MI required new $\mathrm{Q}$ waves on the electrocardiogram that were at least $0.04 \mathrm{~s}$ duration and $0.1 \mathrm{mV}$ in depth, persistent ST-segment depression associated with an elevation in the serum creatine kinase-MB isoenzyme or troponin T. Unstable angina was defined as the appearance of reversible ischemic ST changes (STsegment depression or elevation of $\geq 0.1 \mathrm{mV}$ on the 12-lead electrocardiogram) with typical cardiac symptoms. CHF was defined as clinical and radiologic evidence of acute pulmonary edema, pulmonary wedge pressure elevation during hemodynamic monitoring, or need for major inotropic support.

\section{Statistical Analysis}

The results are presented as mean \pm 1 SD. The Student's t-test or Mann-Whitney U-test was used to compare the means of the continuous variables, and contingency tables were analyzed using a chi-square test. To compare the relative prognostic value of patient variables, multivariate logistic regression analysis was used. A p-value of $<0.05$ was regarded as denoting statistical significance. The computations were performed using the SPSS-PC+ computer program (Version 11.0; SPSS, Chicago, IL, USA).

\section{Results}

\section{Outcome of Aortic Surgery in Relation to Myocardial Imaging}

Of the 302 patients, pharmacologic stress SPECT revealed positive findings in $92(30 \%)$ and negative findings in $210(70 \%)$. The defects were reversible in 64 of the 92 positive patients $(21 \%)$, and were fixed in the remaining 28 patients $(9 \%)$. Preoperative coronary angiography was performed in 33 of the 92 patients with positive SPECT, and a significant stenosis was observed in 25 of them. Of these 25 patients, coronary revascularization was performed before aortic surgery in 9 (coronary artery bypass grafting 


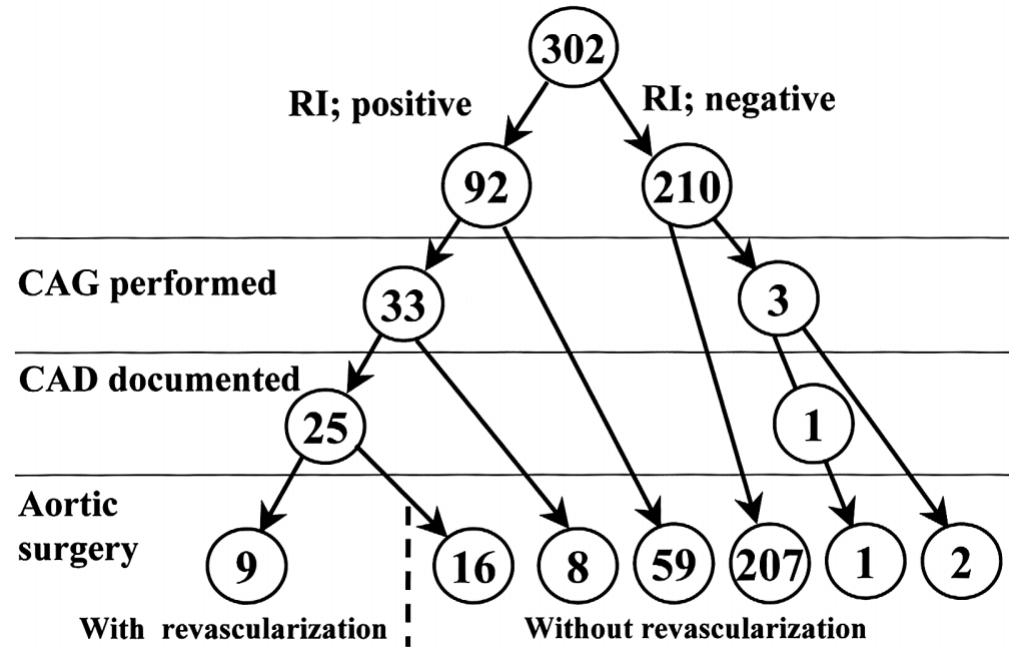

Fig 2. Pharmacologic stress single-photon emission computed tomography revealed negative findings in 210 patients and positives in 92 . Among the 92 patients with positive tests, 33 were evaluated by coronary angiography and 25 were revealed to have significant CAD. Of these 25 patients, 9 underwent successful coronary revascularization prior to endovascular surgery. $\mathrm{CAD}$, coronary artery disease; $\mathrm{CAG}$, coronary angiography; RI, radionuclide imaging.

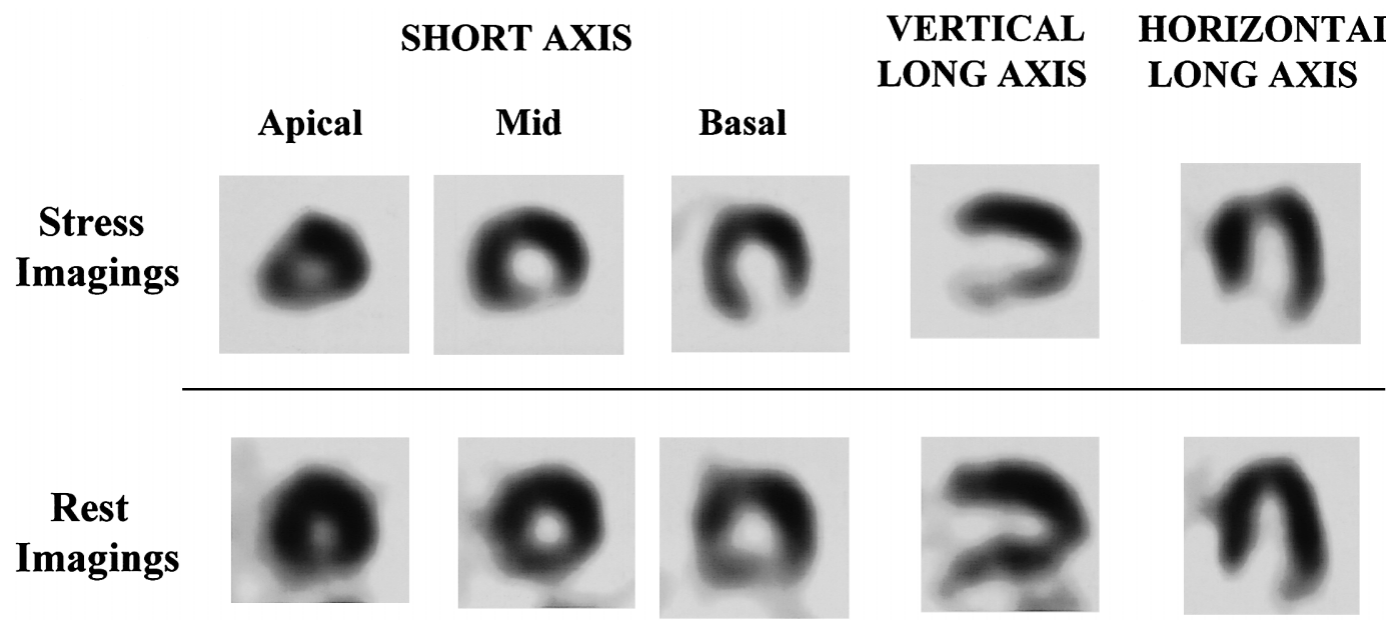

Fig 3. Representative images of tomograms from a patient who underwent preoperative coronary revascularization. A reversible defect can be seen in the anterior, inferior and lateral walls; the SSS was 16. Coronary angiography revealed severe multivessel disease, and percutaneous coronary revascularization was successfully performed prior to aortic surgery. In this patient, aortic surgery was performed safely without any perioperative cardiac event.

Table 1 Characteristics of the 9 Patients With Perioperative Cardiac Events

\begin{tabular}{ccccccccc}
\hline \hline $\begin{array}{c}\text { Patient } \\
\text { no. }\end{array}$ & $\begin{array}{c}\text { Age } \\
\text { (years) }\end{array}$ & $\begin{array}{c}\text { Aortic } \\
\text { disease }\end{array}$ & $\begin{array}{c}\text { Prior } \\
\text { MI }\end{array}$ & $\begin{array}{c}\text { Past } \\
\text { CHF }\end{array}$ & $R D$ & $F D$ & SSS & $\begin{array}{c}\text { Perioperative } \\
\text { cardiac event }\end{array}$ \\
\hline 1 & 69 & $T A A$ & - & + & + & - & 18 & CHF, VF, Death \\
2 & 72 & $A A A$ & + & - & - & + & 29 & Angina, VF, Death \\
3 & 75 & $A D$ & - & + & - & + & 23 & MI, VF, Death \\
4 & 75 & $T A A$ & - & - & + & - & 14 & MI, CHF \\
5 & 73 & $T A A$ & + & - & - & + & 18 & Angina \\
6 & 77 & $T A A$ & - & - & + & - & 12 & Angina \\
7 & 66 & $A D$ & - & - & - & - & 2 & Angina \\
8 & 60 & $A D$ & - & - & - & - & 1 & Angina \\
9 & 69 & $A A A$ & + & - & + & - & 20 & CHF
\end{tabular}

MI, myocardial infarction; $C H F$, congestive heart failure; RD, reversible defect; FD, fixed defect; SSS, summed stress score; TAA, thoracic aortic aneurysm; $V F$, ventricular fibrillation; $A A A$, abdominal aortic aneurysm; $A D$, aortic dissection.

in 7, and percutaneous coronary intervention in 2) because of left main disease or severe multivessel disease (Fig 2). The preoperative pharmacologic stress SPECT in 1 patient who underwent percutaneous coronary intervention before aortic surgery is shown in Fig 3. In 59 patients with positive SPECT, coronary angiography was not performed for the following reasons: 22 patients did not have perfusion defects in the areas perfused by the left anterior descending coronary artery; 28 were asymptomatic because they had undergone coronary angiography in the past few years; 9 were asymptomatic, and had mild perfusion defects and no major risk factor.

Of the 227 patients who underwent deployment of a stent-graft, the procedure was successful in all without the need for surgical conversion, and the other 75 patients underwent conventional open aortic surgery as scheduled. 
Table 2 Preoperative Correlates of a Cardiac Event

\begin{tabular}{|c|c|c|c|}
\hline \multirow[b]{2}{*}{ Variable } & \multicolumn{2}{|c|}{ Cardiac event } & \multirow[b]{2}{*}{ p-value } \\
\hline & $\begin{array}{l}(+) \\
(n=9)\end{array}$ & $\begin{array}{c}(-) \\
(n=293)\end{array}$ & \\
\hline Age (years) & $71 \pm 5$ & $71 \pm 10$ & NS \\
\hline Age $\geq 75$ years & $3(33 \%)$ & $125(43 \%)$ & NS \\
\hline Angina pectoris & $0(0 \%)$ & $19(6 \%)$ & $N S$ \\
\hline Prior myocardial infarction & $3(33 \%)$ & $23(8 \%)$ & $<0.04$ \\
\hline Congestive heart failure & $2(22 \%)$ & $3(1 \%)$ & $<0.01$ \\
\hline Systemic hypertension & $7(78 \%)$ & $210(72 \%)$ & NS \\
\hline Hypercholesteremia & $2(22 \%)$ & $71(24 \%)$ & $N S$ \\
\hline Diabetes mellitus & $1(11 \%)$ & $54(18 \%)$ & $N S$ \\
\hline $\begin{array}{l}\text { Renal insufficiency } \\
\quad(\text { creatinine } \geq 2.0 \mathrm{mg} / \mathrm{dl})\end{array}$ & $1(11 \%)$ & $19(6 \%)$ & $N S$ \\
\hline$Q$ wave on $E C G$ & $2(22 \%)$ & $13(7 \%)$ & NS \\
\hline Positive SPECT & $7(78 \%)$ & $85(29 \%)$ & $<0.01$ \\
\hline Reversible defects & $4(44 \%)$ & $60(20 \%)$ & NS \\
\hline Fixed defects & $3(33 \%)$ & $25(9 \%)$ & $<0.05$ \\
\hline Summed stress score & $15 \pm 9$ & $5 \pm 6$ & $<0.01$ \\
\hline Summed stress score $\geq 14$ & $6(67 \%)$ & $20(7 \%)$ & $<0.0001$ \\
\hline
\end{tabular}

ECG, electrocardiogram; SPECT, single-photon emission computed tomography.

Perioperative cardiac events occurred in 9 of the 302 patients $(3.0 \%)$ : 3 cases of cardiac death $(1.0 \%), 1$ of nonfatal MI, 4 of unstable angina, and 1 of nonfatal CHF (Table 1). Three of these 9 patients had a history of MI, and 2 had a history of heart failure. Seven of the 9 patients had positive SPECT, whereas 2 of the patients who suffered unstable angina had negative SPECT (7/92 vs 2/210; p<0.01). By contrast, neither cardiac death nor MI occurred in patients with negative SPECT.

\section{Prediction for Perioperative Cardiac Events}

The clinical characteristics and scintigraphic findings were compared between patients with and without cardiac events (Table 2). Patients with cardiac events had a high prevalence of a history of congestive heart failure or MI, and positive SPECT findings. Multivariate analysis was performed using 5 variables that were statistically significant by univariate analysis (Table 2 ). The logistic regression analysis revealed that a scintigraphic SSS $\geq 14$ and a history of CHF were the independent predictors for perioperative cardiac events. In particular, the SSS $\geq 14$ was the
Table 3 Independent Predictors of Perioperative Cardiac Events

\begin{tabular}{lccc}
\hline \hline Variable & OR & $95 \%$ CI & p-value \\
\hline Congestive heart failure & 16.4 & $1.4-195.9$ & $<0.03$ \\
Summed stress score $\geq 14$ & 22.5 & $4.9-102.6$ & $<0.001$
\end{tabular}

OR, odds ratio; $C I$, confidence interval.

most important factor to identify patients who subsequently had perioperative cardiac events (Table 3 ). After excluding the SSS, multivariate analysis using only 4 of the variables shown in Table 2 showed that a history of CHF was the most important predictor of perioperative cardiac events (odds ratio 35.9; 95\% confidence interval, 3.7-350.1; $\mathrm{p}<0.01)$. The predictive value of pharmacologic stress SPECT for a cardiac event based only on qualitative findings showed a sensitivity of $78 \%$, specificity of $71 \%$, positive predictive value of $8 \%$, and negative predictive value of $99 \%$. A higher specificity of $93 \%$ and a positive predictive value of $23 \%$ were observed for $\operatorname{SSS} \geq 14$, while the sensitivity of $67 \%$ and a negative predictive value of $99 \%$ did not decrease significantly (Fig 4).

\section{Discussion}

Of the noncardiac surgeries, aortic operations carry one of the highest operative mortalities in Japan: $7 \%$ for thoracic aortic aneurysm and $3 \%$ for abdominal aortic aneurysm. ${ }^{25,26}$ To reduce the incidence of perioperative cardiac events, ACC/AHA Guidelines recommend noninvasive testing of moderate- and high- risk patients undergoing such high-risk surgical procedures $!^{0}$ As exercise testing is contraindicated to patients with aortic aneurysm or dissection, 3 pharmacologic stress SPECT is the noninvasive test of choice, ${ }^{1,3}$ however, preoperative risk stratification for aortic surgery using myocardial perfusion imaging has been seldom reported in Japan! 13,14

The operative mortality and morbidity in the present study were low as only 3 patients (1\%) died and another 6 patients developed nonfatal $\mathrm{MI}$, unstable angina or $\mathrm{CHF}$. The majority of patients were considered to have, at least, intermediate risk for surgery because more than $40 \%$ of them were aged $\geq 75$ years, and also because they had either angina, previous MI, DM or renal insufficiency! ${ }^{10,27}$ The low

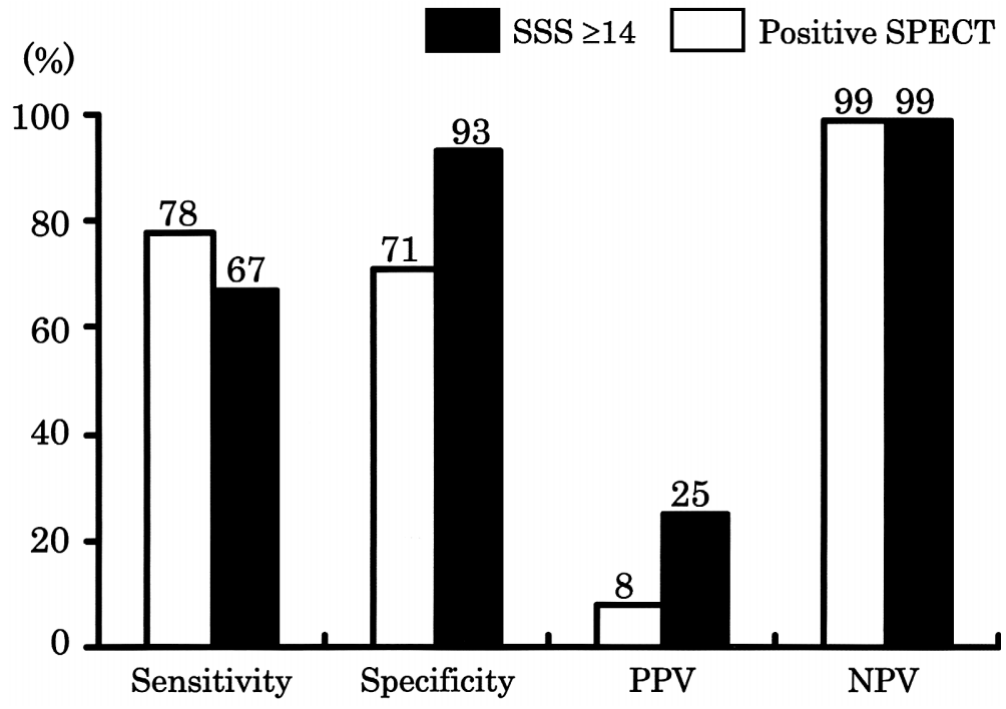

Fig 4. Predictive value of pharmacologic stress SPECT for a cardiac event after aortic surgery. NPV, negative predictive value; PPV, positive predictive value; SSS, summed stress score. 
operative mortality of $1 \%$ observed in this study, despite the patient population and the inclusion of open procedures, may be partly because approximately $70 \%$ of the patients underwent less invasive endovascular surgery; however, it is still lower than the reported operative mortality of $1.9-4.0 \%$ for endovascular surgery $16,18,28$

In the present study, perioperative risk stratification was undertaken using pharmacologic stress SPECT, which was performed safely in all patients. Although clinical features such as previous MI, DM and renal insufficiency are regarded as having a high predictive value for cardiac events, ${ }^{10,27}$ the SPECT finding of a SSS $\geq 14$ was the best predictor in the present study. In addition, 9 patients with left main disease or severe multivessel disease, who were identified as positive by SPECT study underwent successful coronary revascularization before aortic surgery, which was subsequently also performed safely. This approach may have contributed to the reduced operative mortality. By contrast, none of the patients with a negative SPECT finding died or sustained MI during the perioperative period, and there were only 2 patients who suffered unstable angina. Thus, pharmacologic stress SPECT had a high negative predictive value of $99 \%$ for postoperative cardiac events, which is consistent with many previous reports.,6,7,10 Based upon our findings, coronary angiography is strongly recommended before elective aortic surgery for patients with positive preoperative SPECT, in particular, those with SSS $\geq 14$. Furthermore, preoperative coronary revascularization should be considered if necessary.

Recently, the value of pharmacologic stress myocardial imaging for preoperative risk assessment before major vascular surgery was questioned29,30 The patient population in both these studies was younger (63-66 years) than in ours (71 years). Baron et al reported mortality of $4.4 \%$ and morbidity of 19\% in 457 patients who underwent conventional abdominal aortic surgery ${ }^{29}$ and Roghi et al reported mortality and morbidity of $1.5 \%$ and $10.4 \%$, respectively, in 320 patients including 119 open aortic procedures ${ }^{30}$ These incidences of adverse clinical outcomes are higher than the results of our study, caused in part by the invasiveness of the procedure used in each of those studies. In addition, myocardial perfusion imaging was qualitatively assessed for the presence or absence of perfusion defects 29,30 whereas we used a 20-segment SPECT model to evaluate the extent and severity of coronary artery disease ${ }^{21-23}$ Although the presence of extensive reversible defects is important for identifying high-risk patients who require preoperative coronary revascularization, we found that the best predictor for perioperative cardiac events was the model-derived SSS. Thus, preoperative qualitative assessment of myocardial imaging alone may not be sufficient. Full utilization of the advantages of this noninvasive test keeps myocardial perfusion imaging as a valuable modality for preoperative risk stratification before surgical treatment of aortic diseases.

The present study has several limitations that are common to any single center study relying upon retrospective data collection. Most importantly, no uniform indications for coronary angiography or coronary intervention were set. The indications for coronary angiography were decided by the attending physicians based on the conventional patient risk profile. In addition, the decision to perform preoperative coronary revascularization was based predominantly on the results of coronary angiography in association with scintigraphic findings in a clinical conference. Therefore, the influence of potential bias on the results of this study cannot be neglected. Nevertheless, the excellent operative outcome derived from our treatment strategy underlines the clinical importance of preoperative risk stratification using pharmacologic stress SPECT before elective aortic surgery.

\section{References}

1. Shaw L, Miller DD, Kong BA, Hilton T, Stelken A, Stocke K, et al. Determination of perioperative cardiac risk by adenosine thallium201 myocardial imaging. Am Heart J 1992; 124: 861-869.

2. Kontos MC, Brath LK, Akosah KO, Mohanty PK. Cardiac complications in noncardiac surgery: Relative value of resting two-dimensional echocardiography and dipyridamole thallium imaging. Am Heart $J$ 1996; 132: 559-566.

3. Eagle KA, Coley CM, Newell JB, Brewster DC, Darling RC, Strauss $\mathrm{HW}$, et al. Combining clinical and thallium data optimizes preoperative assessment of cardiac risk before major vascular surgery. Ann Intern Med 1989; 110: 859-866.

4. Vanzetto G, Machecourt J, Blendea D, Fagret D, Borrel E, Magne JL, et al. Additive value of thallium single-photon emission computed tomography myocardial imaging for prediction of perioperative events in clinically selected high cardiac risk patients having abdominal aortic surgery. Am J Cardiol 1996; 77: 143-148.

5. Hendel RC, Leppo JA. The value of perioperative clinical indexes and dipyridamole thallium scintigraphy for the prediction of myocardial infarction and cardiac death in patients undergoing vascular surgery. J Nucl Cardiol 1995; 2: 18-25.

6. Lette J, Waters D, Cerino M, Picard M, Champagne P, Lapointe J. Preoperative coronary artery disease risk stratification based on dipyridamole imaging and a simple three-step, three-segment model for patients undergoing noncardiac vascular surgery or major general surgery. Am J Cardiol 1992; 69: 1553-1558.

7. Brown KA, Rowen M. Extent of jeopardized viable myocardium determined by myocardial perfusion imaging best predicts perioperative cardiac events in patients undergoing noncardiac surgery. $J \mathrm{Am}$ Coll Cardiol 1993; 21: 325-330.

8. Etchells E, Meade M, Tomlinson G, Cook D. Semiquantitative dipyridamole myocardial stress perfusion imaging for cardiac risk assessment before noncardiac vascular surgery: A meta-analysis. $J$ Vasc Surg 2002; 36: 534-540.

9. Hashimoto J, Suzuki T, Nakahara T, Kosuda S, Kubo A. Preoperative risk stratification using stress myocardial perfusion scintigraphy with electrocardiographic gating. J Nucl Med 2003; 44: 385-390.

10. Eagle KA, Berger PB, Calkins H, Chaitman BR, Ewy GA, Fleischmann KE, et al. ACC/AHA guideline update for perioperative cardiovascular evaluation for noncardiac surgery-executive summary: A report of the American College of Cardiology/American Heart Association Task Force on Practice Guidelines (Committee to Update the 1996 Guidelines on Perioperative Cardiovascular Evaluation for Noncardiac Surgery). Circulation 2002; 105: 1257-1267.

11. Kouchoukos NT, Dougenis D. Surgery of the thoracic aorta. $N$ Engl J Med 1997; 336: 1876-1888.

12. Eagle KA, Rihal CS, Mickel MC, Holmes DR, Foster ED, Gersh BJ. Cardiac risk of noncardiac surgery: Influence of coronary disease and type of surgery in 3368 operations. Circulation 1997; 96: $1882-$ 1887.

13. Chen T, Kuwabara Y, Tsutsui H, Sasaki M, Nakagawa M, Koga H, et al. The usefulness of dipyridamole thallium-201 single photon emission computed tomography for predicting perioperative cardiac events in patients undergoing noncardiac vascular surgery. Ann Nucl Med 2002; 16: 45-53.

14. Huang Z, Komori S, Sawanobori T, Kohno I, Sano S, Ishihara T, et al. Dipyridamole thallium-201 single-photon emission computed tomography for prediction of perioperative cardiac events in patients with arteriosclerosis obliterans undergoing vascular surgery. Jpn Circ J 1998; 62: 274-278.

15. Shimano T, Kato N, Yasuda F, Suzuki T, Yuasa U, Onoda K, et al. Transluminal stent-graft placements for the treatments of acute onset and chronic aortic dissections. Circulation 2002; 106(Suppl I): I$241-\mathrm{I}-247$.

16. Thompson CS, Gaxotte VD, Rodriguez JA, Ramaiah VG, Vranic M, Ravi R, et al. Endoluminal stent grafting of the thoracic aorta: Initial experience with the Gore Excluder. J Vasc Surg 2002; 35: $1163-$ 1170 .

17. Matsumura JS, Brewster DC, Makaroun MS, Naftel DC. A multicenter controlled clinical trial of open versus endovascular treatment of abdominal aortic aneurysm. J Vasc Surg 2003; 37: 262-271.

18. White RA, Donayre CE, Walot I, Lippmann M, Woody J, Lee J, et al. Endovascular exclusion of descending thoracic aortic aneurysms 
and chronic dissections: Initial clinical results with the AneuRx device. J Vasc Surg 2001; 33: 927-934.

19. Yanagisawa H, Chikamori T, Tanaka N, Usui Y, Takazawa K, Yamashina A. Application of pressure-derived myocardial fractional flow reserve in assessing in assessing the functional severity of coronary artery stenosis in patients with diabetes mellitus. Circ J 2004; 68: $993-998$.

20. Hida S, Chikamori T, Hirayama T, Usui Y, Yanagisawa H, Morishima $\mathrm{T}$, et al. Beneficial effect of coronary artery bypass grafting as assessed by quantitative gated single-photon emission computed tomography. Circ J 2003; 67: 499-504.

21. Hachamovitch R, Berman DS, Shaw LJ, Kiat H, Cohen I, Cabico JA, et al. Incremental prognostic value of myocardial perfusion single photon emission computed tomography for the prediction of cardiac death: Differential stratification for risk of cardiac death and myocardial infarction. Circulation 1998; 97: 535-543.

22. Berman DS, Kang X, Van Train KF, Lewin HC, Cohen I, Areeda J, et al. Comparative prognostic value of automatic quantitative analysis versus semiquantitative visual analysis of exercise myocardial perfusion single-photon emission computed tomography. J Am Coll Cardiol 1998; 32: 1987-1995.

23. Schinkel AF, Elhendy A, Van Domburg RT, Bax JJ, Vourvouri EC, Bountioukos M, et al. Incremental value of exercise technetium-99m tetrofosmin myocardial perfusion single-photon emission computed tomography for the prediction of cardiac events. Am J Cardiol 2003; 91: $408-411$
24. AHA Committee report. A reporting system on patients evaluated for coronary artery disease. Circulation 1975; 51: 5-34.

25. Yada I, Wada H, Shinoda M, Yasuda K. Thoracic and cardiovascular surgery in Japan during 2001: Annual report by the Japanese Association for Thoracic Surgery. Jpn J Thorac Cardiovasc Surg 2003; 51: $699-716$.

26. Shimazaki T, Ishimaru S, Kawaguchi S, Yokoi Y, Saiki N, Watanabe Y. Stent grafting for abdominal aortic aneurysm: Could stent grafting improve the result of treatment in the case of AAA? Jpn J Vasc Surg 2002; 11: 623-627.

27. Lee TH, Marcantonio ER, Mangione CM, Thomas EJ, Polanczyk CA, Cook EF, et al. Derivation and prospective validation of a simple index for prediction of cardiac risk of major noncardiac surgery. Circulation 1999; 100: $1043-1049$.

28. Sicard GA, Rubin BG, Sanchez LA, Keller CA, Flye MW, Picus D, et al. Endoluminal graft repair for abdominal aortic aneurysms in high-risk patients and octogenarians: Is it better than open repair? Ann Surg 2001; 234: 427-437.

29. Baron JF, Mundler O, Bertrand M, Vicaut E, Barre E, Godet G, et al. Dipyridamole-thallium scintigraphy and gated radionuclide angiography to assess cardiac risk before abdominal aortic surgery. $N$ Engl J Med 1994; 330: $663-669$.

30. Roghi A, Palmieri B, Crivellaro W, Sara R, Puttini M, Faletra F. Preoperative assessment of cardiac risk in noncardiac major vascular surgery. Am J Cardiol 1999; 83: 169-174. 